\title{
Evaluation of Different Compressor Control Concepts for a Swash Plate Compressor
}

\author{
Norbert Stulgies ${ }^{\bowtie}$ Manuel Gräber ${ }^{\bowtie}$ Wilhelm Tegethoff ${ }^{\bowtie}$ Sven Försterling ${ }^{\bowtie}$ \\ $\bowtie$ Technical University Braunschweig, Institut für Thermodynamik (IfT) \\ 38106 Braunschweig - Germany \\ $\diamond$ TLK Thermo GmbH, 38106 Braunschweig - Germany \\ n.stulgies@tu-bs.de
}

\begin{abstract}
Due to the development of high efficiency R744 air conditioning systems, the main aim of this paper is the investigation of a control concept for swash plate compressors.
\end{abstract}

This paper presents three different control concepts for a swash plate compressor using a built-in control valve. Therefore a model for a one-phase R744 expansion valve was developed and adapted to detailed measurement data. To achieve high reliability in the simulation, the entire R744 refrigerant cycle was validated using analyses of measurement data from an IfT test bench. The simulation of the refrigeration cycle components was realised using TIL (TLK-IfT-Library). The main focus was set as the description of the compressor with its internal and external mass flow rates. The internal mass flow, which is directed through the crankcase, directly affects the crankcase pressure. It is also called the control mass flow. As a result of the crankcase pressure an adjustable mechanism regulates the displacement as shown in figure 1. The greater the displacement, the greater is the inclination angle. This is caused by different load incidence points on the swash plate e.g. by springs, pistons and pressure states. A comparison of different control concepts shows the characteristic and control behaviour of each of them relating to control time and control mass flow rate. Whenever a control mass flow occurs, it implicates throttle losses. The dissipated energy can be minimised using another control concept.

Keywords: CO2; compressor; control; R744; refrigeration; simulation; valve

\section{Introduction}

In case of different motor speeds, the refrigerant compressor needs to adjust the displacement in order to control the cooling capacity. The adjustment is reached by inclining the swash plate by an angle $\alpha$ as seen in figure 1. The inclination itself is a function of the balance of forces. Besides the friction, inertia and spring forces, the pressure difference between the crankcase and the cylinder capacity has the greatest influence. Thus the target is to control the aforementioned pressure difference by controlling the crankcase pressure. The control mechanism of a swash plate compressor separates a part of the cooling mass flow of the refrigerant cycle at the discharge chamber and leads it through a valve to the crankcase. Another valve seated between the crankcase and suction chamber completes the control path of the compressor. Depending on the throttle devices used in the two throttle locations, different control strategies can be realised. Throttle devices can be either simple orifices or proportional valves.

\section{TIL}

TIL is a component model library for thermodynamic systems that was developed by the Institute for Thermodynamics (IfT) and TLKThermo-GmbH, and allows steady-state and transient simulation of thermodynamic systems. The library provides miscellaneous models of thermal and fluid technology components, as well as transport phenomena. Media properties can be included by using the TILMedia library or Refprop media data. The structure of TIL is an independent library-modelling concept, which due to its shallow inheritance structure, permits designers 


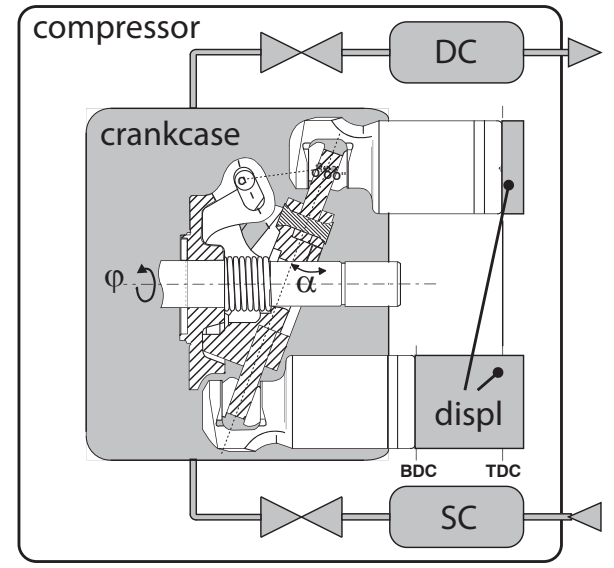

Figure 1: Swash plate mechanism with driven shaft, pistons, suction chamber, discharge chamber and displacement

as well as simulation specialists to achieve fast, suitable models.

\section{Cycle Layout}

In order to model a cycle, some components used from TIL, and some were made for the specific problem. In the following section, the components are described in more detail. All components can run in both flow directions. More specific information about TIL is in Richter2008 [Ric08]. The complete cycle is shown in figure 2 . The implemented models for the external heat exchangers use a cross flow scheme. To create a heat exchanger having more than one path it is possible to use the required number of serial connected models. In the investigated cycle, a gas cooler with two paths was used. The discretisation level on the refrigerant side was ten cells per path. The internal heat exchanger (IHX), was realised by using a tube in tube construction with discretisation level 10 , and connecting the heat port of every cell in one tube with another heat port from the second tube in such a manner that a counter flow heat exchanger is realised. The flow through the expansion valve can be specified using the Bernoulli equation. The accumulator offers the possibility to store refrigerant at different operating points. The compressor model describes a variable displacement compressor which can be characterised by an efficiency based approach. The used efficiencies are the volumetric efficiency, isentropic efficiency and quality grade. The efficiencies are accessible in a compressor characteristic plot. The calculation of the displacement is an iterative process of pressure states in the crankcase, suction chamber and discharge chamber. In the model considered, perturbances are caused by internal leakage that means the blowing by of gas through the piston clearance, which shows ordinary values of $0.0004 \mathrm{in} /$ in of diameter for steel pistons up to $0.002 \mathrm{in} /$ in of diameter for aluminium pistons without piston rings [AAD00]. Although these flows are very small compared with the cooling mass flow rate, the influence on the control mass flows is not negligible. A characteristic property is the non-continuous behaviour of these flows.

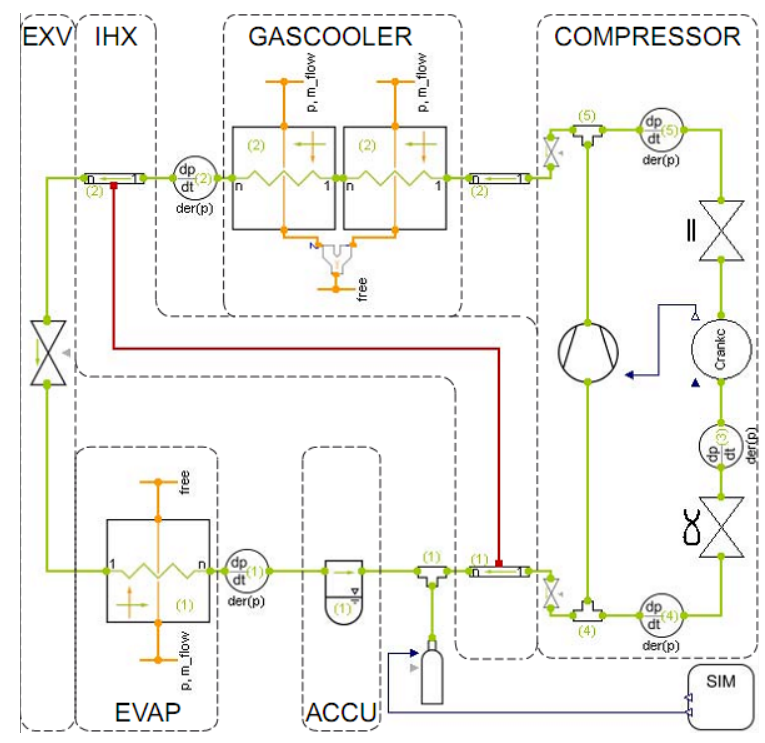

Figure 2: Schematic diagram of the Modelica model of concept A

\section{Compressor Submodels}

The simulation of the thermodynamical and mechanical behaviour of a mobile air conditioning compressor is computationally very intensive. The first reason for this is the complicated equations of motion of the swash plate mechanism. The second and far more significant reason for this condition is the media data, which have to be calculated in every of the several (in this case 7) displacement chambers with a very small time constant. The complexness of all is the strong causal dependence of these two effects. The interdepence of the pistons was in this model neglected. An complete consideration can be find in [Cav08].To simplify the model, detailed calculations of the swash plate mechanism behaviour were done beforehand. The 
analysis of the calculation leads to simple trigonometric equations which describe the mechanism of the compressor. There are four main effects which have an impact on the mechanism and its moment balance system. At any time the moment balance of the swash plate has to be zero.

\section{- Adjusting springs}

The moment due to the springs, with one displacement increasing and another decreasing, is the sum of the spring forces multiplied by a constant lever. The function has the following appearance. $M_{\text {springs }}=f(\alpha)$

- Deviation moment of the swash plate The swash plate is fixed to the driving shaft by a swing bearing which allows inclination by an angle $\alpha$. Depending on the inclination angle, the moment which forces the swash plate to a position perpendicular to the driving shaft increases with an increasing speed. The expression which is described as well in Valeo [Val] is shown here:

$$
M_{d e v}=\frac{m_{S W P}}{12} \cos (\alpha) \sin (\alpha)\left(3 r_{a}^{2}+3 r_{i}^{2}-h^{2}\right)
$$

\section{- Piston inertia}

The piston inertia contributes a moment to the swash plate that increases the angle of the swash plate and hence the displacement of the compressor. The observation of the moment caused by a single piston shows a periodic moment to the swash plate related to one turn. The moment resulting from all the pistons together shows an almost constant moment to the swash plate. The only influencing variables are the compressor speed and the angle of the swash plate, so that the moment due to inertia is a function like this: $M_{\text {piston inertia }}=$ $f(\alpha(t), \dot{\alpha}(t), \ddot{\alpha}(t), \varphi(t), \dot{\varphi}(t), \ddot{\varphi}(t))$.

Assuming $\ddot{\varphi}(t)$ is negligible leads to the following expression where $\mathrm{M}$ is a linear function of the swash plate angle and has a quadratic dependency on the speed:

$$
M_{p \text { inert }}=\sum_{i} m_{i} \cdot \ddot{x}(\alpha(t), \varphi(t)) \cdot r_{i}(\varphi)_{i}
$$

A chosen piston mass of $55 \mathrm{~g}$ including the piston slide shoes results in the implemented expression in Modelica:

$$
\begin{aligned}
M_{\text {inertia }}=\left(c_{0} \alpha+c_{1}\right) & n^{2}+\left(c_{2} \alpha+c_{3}\right) n+ \\
\left(c_{4} \alpha+c_{5}\right) & \\
\text { where } c_{0} & =-1.01 \mathrm{e}-9 \\
c_{1} & =5.68 e-11 \\
c_{2} & =1.01 e-17 \\
c_{3} & =-5.32 E-1 \\
c_{4} & =-7.67 e-15 \\
c_{5} & =4.76 e-16
\end{aligned}
$$

\section{- Pressure loads}

The pressure loads consider all forces or moments caused by the pressure differencees over the pistons. These pressure differences are given by the pressure in the crankcase and the currently obtaining pressure in the displacement chamber. In this model an expression was derived, which describes the torque to the swash plate without calculating the state variables in the displacement chamber. The thus found equation depends only on the quite slowly changing state variables of the cooling circuit or the much more idle volume of the crankcase.

$$
\begin{aligned}
& M_{d p}=\left((-0.5742 \pi+0.3449) p_{s}+\right. \\
& \left.\quad\left(\arctan \left(\left(\pi+k_{0}\right) k_{1}\right) k_{2}+k_{3}\right)\right)+ \\
& 3.82536\left(p_{\text {crankcase }}-p_{s}\right) \\
& \text { where } \\
& k_{0}=0.0045 \alpha^{2}-0.1372 \alpha-2.2008 \\
& k_{1}=25 \\
& k_{2}=-0.0195 \alpha^{2}+0.5915 \alpha+0.606 \\
& k_{3}=-0.0316 \alpha^{2}+0.9524 \alpha+1.471
\end{aligned}
$$

\section{Control Concepts}

In figure 3, three different control concepts are shown. Concept A presents the combination of an orifice at the high pressure side, i.e. between the discharge chamber and crankcase, and a proportional valve at low pressure side, which is situated between the crankcase and suction chamber. Concept B shows the opposite assembly. In the third example, concept $\mathrm{C}$, the application of two proportional valves is shown. 


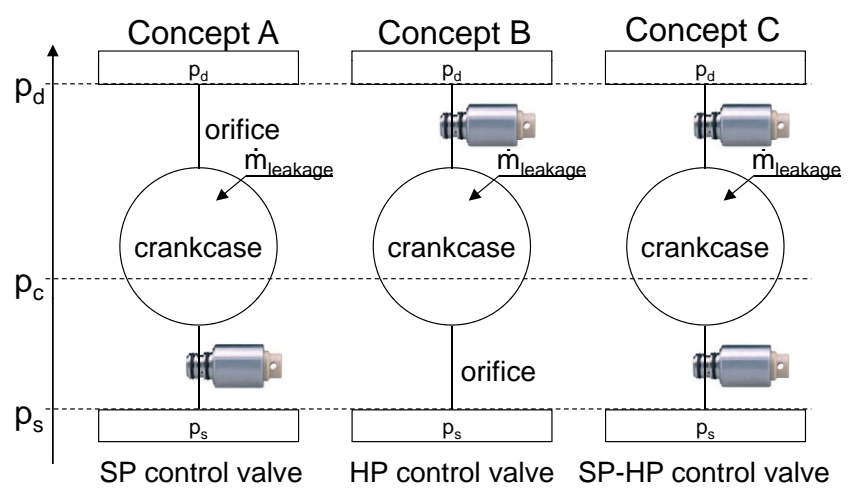

Figure 3: Visualisation of the three control concepts [NS08]

It is quite simple to come to the conclusion, that concept $\mathrm{C}$ has to be the best one. The explanation for that is that concept $\mathrm{A}$ and $\mathrm{B}$ have a continuous control mass flow rate of in steady state conditions, whereas concept $\mathrm{C}$ shows no control mass flow rate for this case. To simulate more realistic conditions, perturbances such as blowing by flows at the pistons are considered. These are shown in figure 3 as leakage mass flow rates.

A comparison of the three different control concepts was carried out using an identical maximum mass flow rate through the control valves. For concept $\mathrm{A}$ and $\mathrm{B}$, simulation results are shown in figure 4 and figure 5 .

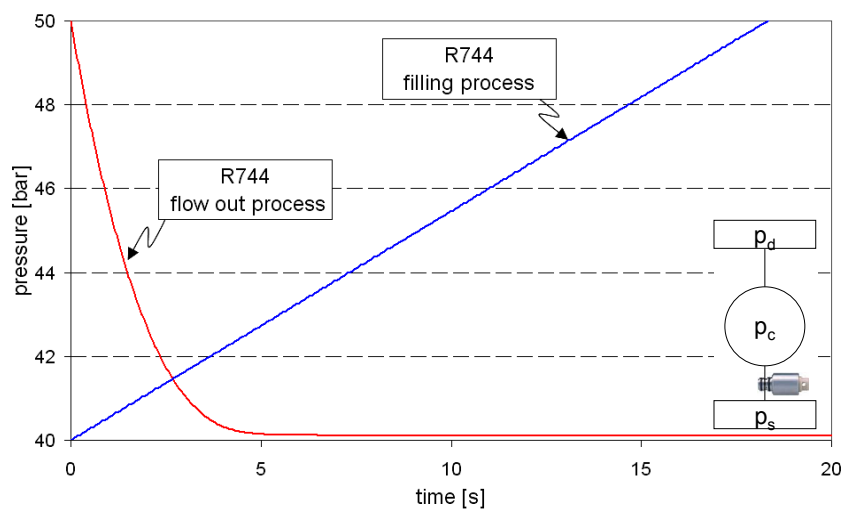

Figure 4: Filling process (proportional valve is closed) and flow out with open valve

In figure 6 the sequence flow for the control of the evaporator air outlet temperature is shown. The above written equations are all included in the compressor. More exactly in the adjusting process of the swash plate.

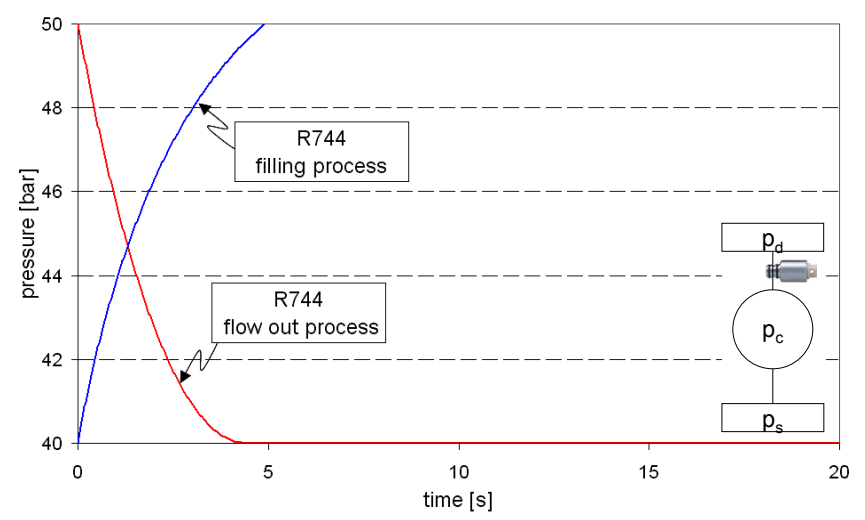

Figure 5: Filling process (proportional valve is open) and flow out with closed valve

\section{Transient Simulation of the System}

In the following, results of the transient simulation of the above mentioned $\mathrm{CO}_{2}$-system are presented. The transient data of the $\mathrm{CO}_{2}$-cycle was measured by using the input data of speed and air velocities from CADC (Commen Artemis Driving Cycle) [BM07]. The CADC shows much more transient behaviour than the commen NEDC, and thus the influence of the different control concepts show different results in control behaviour.

In figure 7 the simulation results of the evaporator air outlet temperature controlled CAD-Cycle are shown. The controller of the outlet temperature was realised using an integrator controller. The necessary control mass flow related to the effective cooling mass flow shows effective cooling losses of about $6.1 \%$.

In figure 8 the simulation results of the compressor sensitivity are shown. The proportional control valve of the compressor (concept B) was regulated by current. The first simulation shows the response characteristic of the compressor in idle mode and a constant control current. The second simulation shows the influence of a sineshaped varying control mass flow. A modification of the control mass flow shows a gain in influence of the swash plate angle. The variation of the mass flow by approximately $1 \%$ leads to responses of the relative displacement up to $10 \%$.

\section{Conclusion}

In this paper a refrigeration cycle was modeled and validated by measurement data. The focus 


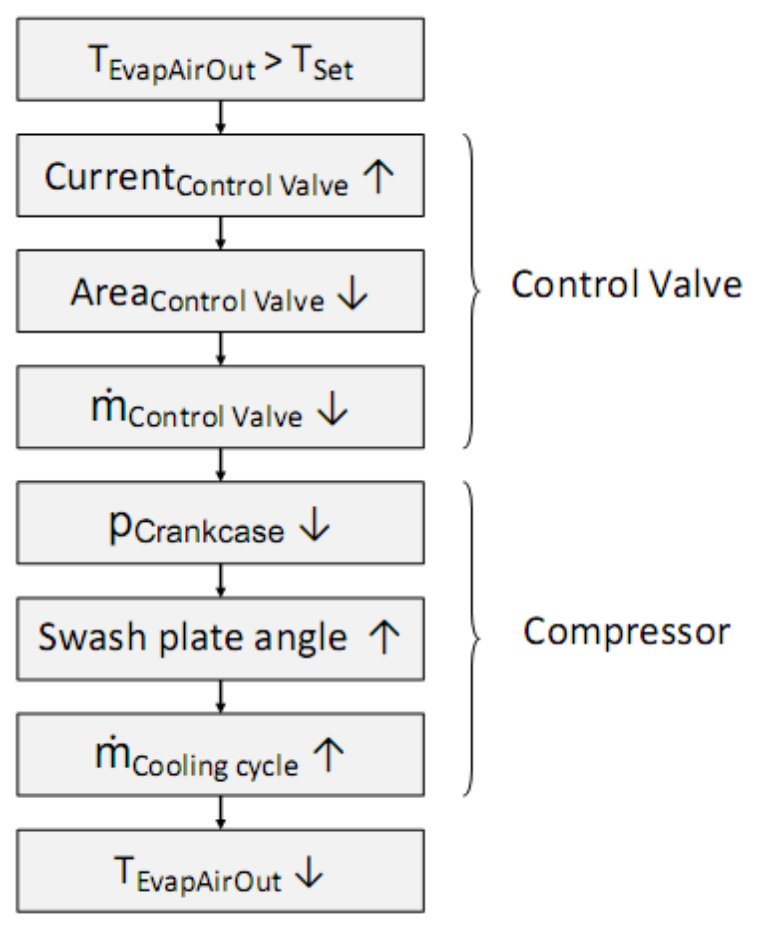

Figure 6: Sequence flow of an evaporator air outlet temperature controlled cooling cycle. The control Valve is an normally opened valve mounted in between the discharge chamber and the crankcase (concept B)

was set to the compressor especially to the adjusting mechanism in the crankcase. For that, equations for the momentum balance of the swash plate were derived. With this model the presented concepts can be compared related to efficiency and comfort.

\section{References}

[AAD00] Albert A. Domingorena, Dean H. Rizzo, John H. Roberts Rudy Stegmann Jaroslav Wurm: The 2000 ASHRAE Handbook, 34 - Compressors, 34.1-34.36. ASHRAE, 2000.

[BM07] Boulter, Paul IAn McCrae: Assessment and reliability of transport emission models and inventory systems. , TRL Limited, October 2007.

[Cav08] Cavalcante, Peterson: Instationäre Modellierung und Sensitivitätsanalyse regelbarer CO2-Axialkolbenverdichter. , 2008.

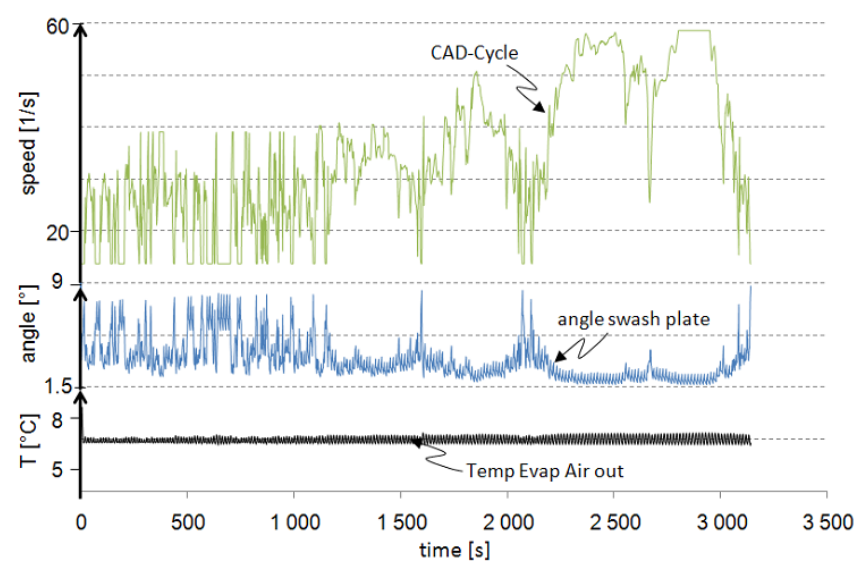

Figure 7: Simulation results of Concept B. The green shape shows the speed of the compressor the blue one the resulting swash plate angle. The black curve shows the simple controlled temperature outlet response.

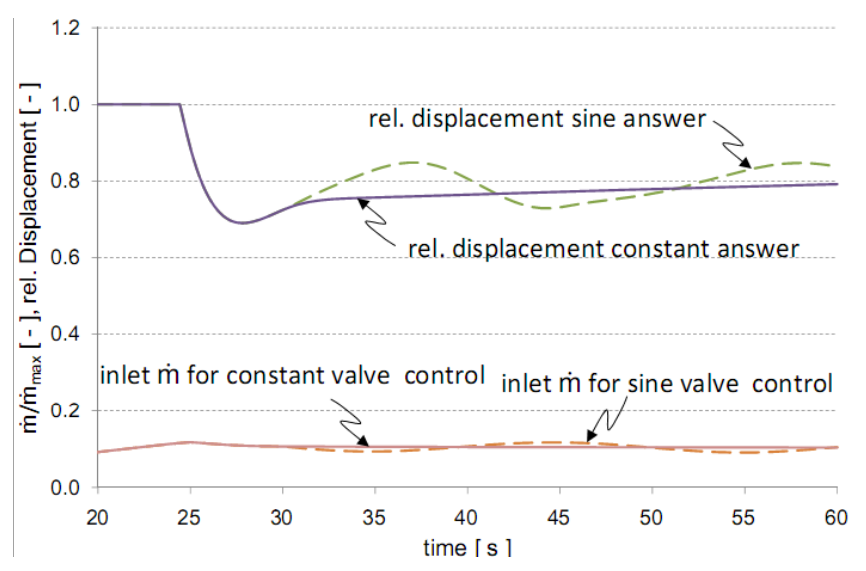

Figure 8: Identifying the swash plate angle response due to a control mass flow variation

[NS08] Norbert Stulgies, Axel Müller, Horst Kappler Wilhelm TegethOFF SVEN FÖRSTERLING JÜRGEN KÖHLER: Proposal for efficient characterization of $(R) 744$ compressor control valves. 2008.

[Ric08] Richter, Christoph: Proposal of New Object-Oriented Equation-Based Model Libraries for Thermodynamic Systems. , 2008.

[Val] VALEO: Verfahren zum Regeln des Kältemittel-Massenstroms eines Verdichters. 